\title{
Políticas públicas e mobilização social no contexto do desastre no Rio Doce
}

\author{
Luciana Andressa Martins de Souza \\ Universidade Federal do Espírito Santo - Vitória - Espírito Santo - Brasil \\ Euzeneia Carlos \\ Universidade Federal do Espírito Santo - Vitória - Espírito Santo - Brasil
}

\section{Resumo}

Visa a analisar as mudanças na ação coletiva da sociedade civil e nos seus padrões de relação com o Estado, emergentes no contexto pós-desastre socioambiental no Rio Doce. Busca compreender as ações do Estado e a participação da sociedade civil neste contexto, considerando os instrumentos de políticas públicas e o surgimento de diversos formatos de mobilização. O objeto empírico é definido pelas decisões dos atores estatais em diferentes arenas e níveis federativos e pelos fóruns de mobilização social e audiências públicas nos municípios de Linhares, Colatina e Baixo Guandú, no Espírito Santo. Assume-se o pressuposto teórico de que as mudanças na sociedade civil, no Estado e nas políticas públicas se constituem reciprocamente e incidem nos padrões de ação coletiva e de interação com o Estado. Em termos metodológicos, a pesquisa combina métodos quantitativos e qualitativos e um conjunto de técnicas de pesquisa e instrumentos de processamento de dados. Os resultados permitem apreender os processos de inovação organizacional e de mudança institucional que não seriam possíveis em outros contextos, dada a excepcionalidade das conjunturas críticas para a produção de novas oportunidades políticas tanto para a sociedade civil quanto para o Estado.

Palavras-chave: Desastre socioambiental. Instituições participativas. Sociedade civil. Instrumentos de políticas.

\section{Public policies and social mobilization in the context of the Rio Doce disaster}

\begin{abstract}
This article aims to analyze changes in the collective action of civil society and in patterns of its relationship with the State as they emerge in the post-disaster socio-environmental context regarding the Rio Doce disaster. It seeks to assess the actions of the State and the participation of civil society in this context, with consideration given to the instruments of public policy and the emergence of diverse forms of mobilization. The empirical object is defined by the decisions of state actors in different arenas and at federative levels, as well as by the forums of social mobilization and public audiences in the municipalities of Linhares, Colatina, and Baixo Guandú in Espírito Santo. The theoretical assumption is that changes in civil society and state and public policies are reciprocally constituted, and affect patterns of collective action and interaction with the state. In methodological terms, the research
\end{abstract}


combines quantitative and qualitative methods with a set of research techniques and data processing instruments. The results allow us to grasp the processes of organizational innovation and institutional change that would not be possible in other contexts, given the exceptionality of critical conjunctures for the production of new political opportunities for both civil society and the state.

Keywords: Social and environmental disaster. Public Policies. Civil society. Instruments of public policy.

\section{Políticas públicas y movilización social en el contexto del desastre en Río Doce}

\section{Resumen}

Se trata de analizar los cambios en la acción colectiva de la sociedad civil y en sus patrones de relación con el Estado, emergentes en el contexto post-desastre socioambiental en el Río Doce. En este contexto, busca comprender las acciones del Estado y la participación de la sociedad civil en este contexto, considerando los instrumentos de políticas públicas y el surgimiento de diversos formatos de movilización. El objeto empírico se define por las decisiones de los actores estatales en diferentes arenas y niveles federativos y por los foros de movilización social y audiencias públicas en los municipios de Linhares, Colatina y Bajo Guandú, en Espírito Santo. Se asume el supuesto teórico de que los cambios en la sociedad civil, en el Estado y en las políticas públicas se constituyen recíprocamente e inciden en los patrones de acción colectiva y de interacción con el Estado. En términos metodológicos, la investigación combina métodos cuantitativos y cualitativos, además de un conjunto de técnicas de investigación e instrumentos de procesamiento de datos. Los resultados permiten aprehender los procesos de innovación organizacional y de cambio institucional que no serían posibles en otros contextos, dada la excepcionalidad de las coyunturas críticas para la producción de nuevas oportunidades políticas tanto para la sociedad civil y para el Estado.

Palabras clave: Desastre socioambiental. Políticas públicas. Sociedad civil. Instrumentos de política.

\section{Introdução'}

Este artigo visa a analisar as mudanças institucionais e organizacionais dos atores estatais e da sociedade civil, emergentes no contexto pós-desastre socioambiental no Rio Doce, provocado pelo rompimento da barragem de rejeitos de minério de Fundão, em Mariana (MG), das mineradoras Samarco, Vale e BHP.

No dia 05 de novembro de 2015 o rompimento da barragem de contenção de rejeitos de mineração de Fundão, no distrito de Bento Rodrigues em Mariana (MG), das empresas mineradoras Samarco, Vale e BHP Billiton, provocou o maior desastre socioambiental do país e um dos maiores do mundo, despejando cerca de 50 milhões de m3 de lama nos rios Carmo e Doce. O desastre incidiu diretamente na Bacia

\footnotetext{
${ }^{1}$ Este artigo é resultado parcial das pesquisas intituladas: "Sociedade civil, Estado e políticas públicas no contexto do desastre no Rio Doce" (Edital FAPES Universal Nº3/2017); "Sem o rio e sem o mar: implementação de tecnologia social de governança participativa para políticas públicas de recuperação da Bacia do Rio Doce no Espírito Santo (Chamada CAPES-CNPq-FAPEMIG-FAPES-ANA N 06/2016); e "O papel dos partidos políticos nas suas interações com as instituições participativas e os movimentos sociais na construção de políticas públicas para a recuperação da Bacia do Rio Doce" (Edital FAPES/CNPq No 22/1018). Versões preliminares foram apresentadas no 110 Encontro da ABCP, Curitiba, 31 de julho a 3 de agosto de 2018, e no $42^{\circ}$ Encontro da ANPOCS, Caxambu, 22 a 25 de outubro de 2018 (Cf. CARLOS; SOUZA, 2018; SOUZA; CARLOS, 2018).
} 
Hidrográfica do Rio Doce e ecossistemas associados, atingindo 41 municípios de Minas Gerais e do Espírito Santo através da poluição hídrica, mortandade de animais e interrupção de abastecimento de água. A lama de rejeitos percorreu o caminho da calha do Rio Doce até sua foz no mar, deixando um rastro de destruição nos municípios de Ipatinga, Governador Valadares e Resplendor, em Minas Gerais, e em Baixo Guandú, Colatina e Linhares, no Espírito Santo. No território capixaba, após atingir Mascarenhas (Baixo Guandú), no dia 16 de novembro, a lama de rejeitos chegou ao Oceano Atlântico através da foz Sul em Regência (Linhares), no dia 22 de novembro, seguido pela foz Norte em Barra Seca (São Mateus), tendo a pluma de lama afetado áreas em Aracruz, Fundão e Serra. A Figura 1 apresenta a cronologia do desastre e o percurso da lama de rejeitos, de Minas Gerais ao Espírito Santo.

Figura 1. Cronologia do desastre socioambiental e percurso da lama de rejeitos no Rio Doce

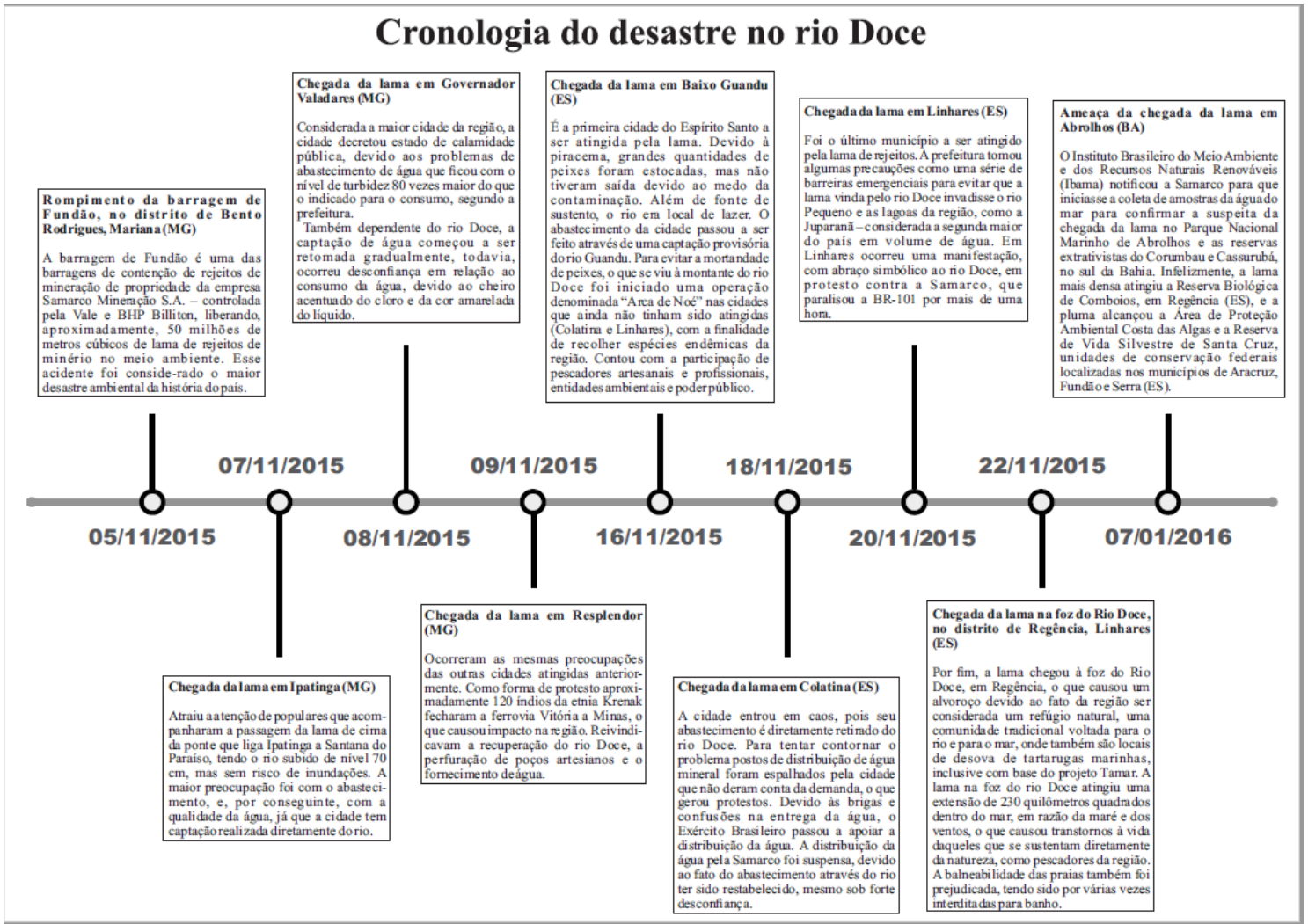

Fonte: Elaboração própria a partir de notícias de jornais publicadas entre 05/11/2015 a 07/01/2016.

O desastre socioambiental no Rio Doce foiçou vidas (19 ao total) e destruiu o meio ambiente e ecossistemas. Estima-se que mais de 29.300 carcaças de peixe foram coletadas e cerca de 240,88 hectares de Mata Atlântica foram degradados 2 . Dentre os humanos atingiu sobretudo as populações mais vulneráveis, inviabilizando a subsistência das famílias de ribeirinhos e de pescadores que retiravam seu sustento do rio e do mar, em algumas áreas, de comunidades tradicionais de indígenas e quilombolas, além de outros territórios rurais e de segmentos econômicos nas cidades, atingindo todos os moradores, ainda que em intensidades variadas. $O$

2 Informações divulgadas pelo site do MPF, disponível em: http://www.mpf.mp.br/para-ocidadao/caso-mariana/o-desastre. 
desastre transformou seus modos de vida, de trabalho e de organização social, com consequências irreparáveis à memória do lugar, às transmissões de aprendizados entre gerações, ao sentimento de pertencimento e de vínculo social. Negou às populações atingidas os direitos de cidadania e os direitos à dignidade da pessoa humana. Nesta negação de direitos, as desigualdades de raça, de gênero e social são reproduzidas nos diferentes lugares e tempos do desastre, aprofundando as afetações sobretudo nas comunidades tradicionais e nas áreas socialmente vulneráveis. Conforme aponta a perspectiva de justiça ambiental, os impactos do desastre são desigualmente distribuídos na sociedade tendo em vista as assimetrias sociais e econômicas que caracterizam as formas de apropriação e usos dos territórios e de seus recursos (ACSELRAD, 2004). Incorre ainda como um racismo ambiental, dada a tendência de intensificação das situações de risco que atingem populações predominantemente negra ou grupos étnicos mais vulneráveis, historicamente marginalizadas (ZHOURI, 2008).

Os estudos sobre os impactos deste desastre socioambiental de grande magnitude destacam os danos econômicos, sociais, culturais e simbólicos das populações de atingidos, urbanas e rurais, sobretudo de comunidades tradicionais de pescadores, agricultores ribeirinhos, indígenas e quilombolas que viviam do rio e com o rio. No Espírito Santo, os impactos sociais do rompimento da barragem têm sido enfatizados nos relatórios de pesquisa que apontam para um processo de mudança social nos municípios afetados, com transformações nos modos de trabalho, na convivência familiar e social e nas formas de organização da vida comunitária (LOSEKANN, 2015; FERREIRA, 2016). Efeitos socioambientais decorrentes do desastre também são apontados, como alterações na percepção dos moradores sobre o ambiente e a emergência da percepção de risco à subsistência e à segurança alimentar das comunidades (LEONARDO et. al., 2017).

As empresas Samarco, Vale e BHP foram responsabilizadas pelo desastre e mais de 20 pessoas envolvidas foram denunciadas pelo Ministério Público Federal (MPF) por crimes de inundação, desabamento, lesão corporal, crimes ambientais e homicídio qualificado, mas até hoje os processos seguem na justiça e ninguém foi preso. Uma série de medidas emergenciais e ações foram ajuizadas até que em março de 2016 foi celebrado o Termo de Transação e Ajustamento de Conduta (TTAC) entre a União, os governos estaduais de Minas Gerais e Espírito Santo e as três empresas envolvidas. É importante sublinhar que o acordo estabeleceu 40 programas de restauração, mitigação e compensação dos danos causados, os quais deveriam ser geridos e executados por uma fundação de caráter privado criada para esta finalidade, denominada Fundação Renova, tendo criado ainda o Comitê Interfederativo (CIF) 3 e 10 Câmaras Técnicas para apoiar, supervisionar, monitorar, fiscalizar e validar essas ações (ZORZAL; CAYRES; SOUZA; 2017, p. 10). No entanto, o TTAC foi um acordo elaborado sem a participação dos atingidos, sofreu questionamentos de movimentos sociais e organizações civis e não foi assinado pelo Ministério Público (MP). Neste processo de negociação foi firmado o Termo de Ajustamento Preliminar (TAP), em janeiro de 2017, assinado pelo Ministério Público Federal (MPF) e as três empresas. Logo depois foi firmado o Termo Aditivo ao TAP

3 O CIF é composto de representantes de órgãos públicos do Poder Executivo Federal, Estadual e dos municípios afetados. 
incluindo além do MPF e as empresas, o Ministério Público de Minas Gerais (MPMG) e o Conselho Nacional de Direitos Humanos (CNDH). No Termo Aditivo, a questão da participação dos atingidos nas negociações e as Assessorias Técnicas aos atingidos é tematizada. Seguida de diversas audiências públicas, oficinas e grupos de trabalho empreendidos pelo MPF juntamente com atores da sociedade civil foi firmado, no último dia 25 de junho de 2018, um novo acordo entre o MPF, Ministério Público Estadual de MG e ES, Defensoria Pública da União, Defensoria Pública de Minas Gerais, Defensoria Pública do Espírito Santo, mais 09 órgãos públicos e as empresas envolvidas: o TAC Governança. Esse TAC alterou o processo de governança do TTAC para definição e execução das diversas ações, programas e projetos de reparação dos danos causados; prevê a criação de novas estruturas de participação das pessoas atingidas em todas as etapas e fases do TTAC, e a contratação de assessoria técnica para os atingidos; e possibilita o eventual estabelecimento de um novo processo de negociação dos programas já em curso sob responsabilidade da Fundação Renova 4 .

É considerando este contexto de desastre socioambiental, seus múltiplos impactos, responsabilizações e acordos de reparação e mitigação dos danos que a questão de pesquisa deste artigo se coloca, a saber: Quais as principais ações empregadas pelos governos municipais e estaduais e pelos atores da sociedade civil emergentes neste contexto?

\section{Mudanças organizacionais e institucionais no contexto de "conjuntura crítica" posterior ao desastre}

Neste artigo, partimos do conceito de "conjuntura crítica” (critical juncture) para interpretar o espaço-tempo do desastre socioambiental do Rio Doce como uma situação de "catástrofe", embora ainda sem incorporar uma explicação comparada entre os eventos pregressos e pós-desastre na qual o mesmo se sedimenta. Segundo Mahoney e Thelen (2010, p.7), a conjuntura crítica pode ser analisada como uma configuração particular que facilita a ação de agentes capazes de introduzir novas ideias, modelos ou políticas alterando a trajetória das instituições.

Focamos em parte dessa abordagem, portanto, ao argumentarmos que diante de situações graves e urgentes, como o desastre socioambiental em questão, a administração pública em seus diferentes níveis federativos (municipal, estadual e federal) e arenas (executivo, legislativo e sistemas de justiça) pode produzir regras, normas e procedimentos de forma rápida e imediata, impactando na linearidade, normalidade e normatividade das suas ações. Por outro lado, a conjuntura crítica do desastre abriria oportunidades para atores da sociedade civil, possibilitando a emergência de formas de mobilização, de participação e de ativismo, além de ensejar mudanças nos padrões de interação socioestal. Se, no contexto de conjuntura crítica, as ações dos governos aceleram ou alteram as medidas que o próprio governo vinha conduzindo ou se a atuação da sociedade civil constitui mudanças ou inovações na ação coletiva são elementos a serem investigados nos próximos estudos, mediante a análise comparada com eventos históricos e pregressos.

4 Informações divulgadas pelo site do MPF, disponível em: http://www.mpf.mp.br/para-ocidadao/caso-mariana/o-desastre. 
Neste diapasão torna-se possível compreender as mudanças institucionais e organizacionais mediante a investigação das ações coletivas emergentes e dos padrões de interação entre as instituições e os atores na produção de políticas públicas voltadas à reparação dos danos e à reconstrução dos modos de vida das comunidades atingidas pós-desastre. Naturalmente, não imune às implicações das formas pretéritas de organização da sociedade civil e do legado histórico das instituições e atores estatais.

O enfoque de política pública utilizado pode ser resumido na célebre frase de Jobert e Muller (1987): o estudo do “Estado em ação". Segundo Marques (2013, p.24) "estudar políticas é analisar por que o Estado age como age, dadas as condições que o cercam". Para Souza (2006, p.26) "debates sobre políticas públicas implicam responder à questão sobre o espaço que cabe aos governos na definição e implementação de políticas públicas". É importante sublinhar que não nos apoiamos nas visões pluralista, elitista, estruturalista e funcionalista do Estado e sim no debate neoinstitucionalista que defende o papel da autonomia relativa do Estado na criação de determinadas capacidades (Evans, Rueschmeyer e Skocpol, 1985) que conectam o Estado e a sociedade e provêem as condições para negociação dos objetivos das políticas públicas.

O problema de pesquisa versa sobre a racionalidade das múltiplas interações estabelecidas entre diferentes atores sociais, políticos e instâncias institucionais emergentes no contexto de conjuntura crítica pós-desastre. Neste propósito, a compreensão da relação entre os atores da sociedade civil e as instituições e atores estatais é relevante haja vista o contexto de emergência de modalidades de ação coletiva e de configurações da participação, tendo em vista a produção de decisões governamentais que são analisadas sob a ótica dos instrumentos de políticas públicas orientados pelos interesses e aspirações dos atores envolvidos nas disputas contenciosas (HALPERN, LE GALÈS, 2011; LASCOUMES, LE GALÈS, 2007). Assume-se o pressuposto, próprio das abordagens centradas em interações socioestatais, de que as mudanças na sociedade civil, no Estado e nas políticas públicas se constituem reciprocamente e incidem nos padrões de ação coletiva e de interação com o Estado (GURZA LAVALLE, CARLOS, DOWBOR, SZWAKO, 2017; GURZA LAVALLE, HOUTZAGER, CASTELLO, 2011; SKOCPOL, 1992).

O objeto empírico é definido pelos instrumentos de políticas públicas adotados em diferentes arenas e níveis federativos e pelos fóruns de mobilização social nos municípios de Linhares, Colatina e Baixo Guandú, no Espírito Santo. No primeiro caso, consistiram nos conselhos de políticas públicas inicialmente, mas se estenderam para outros instrumentos de políticas públicas instituídos após o desastre. No segundo, formado pelo Fórum Capixaba de Defesa do Rio Doce, Fórum SOS Rio Doce, Fórum Foz Norte e Fórum Foz Sul, e pelas Audiências Públicas.

Os instrumentos de políticas públicas instituídos após o desastre são examinados a partir de seu processo de decisão (LASCOUMES, LE GALÈS, 2007; GURZA LAVALLE, VOIGT, SERAFIM, 2016). Ao passo que os fóruns de mobilização social e as audiências públicas são analisados a partir da perspectiva dos movimentos sociais, organizações e atores sociais participantes, considerando três categorias: enquadramento interpretativo, repertórios de ação coletiva e redes de ativismo (BENFORD, SNOW, 2000; TILLY, TARROW, 2007; DIANI, BISON, 2010). 
Em termos metodológicos, a pesquisa combina métodos quantitativos e qualitativos (mixed method research) e um conjunto de técnicas de pesquisa e de processamento de dados. As análises quantitativas são aplicadas aos instrumentos de políticas públicas e têm como base as informações censitárias, como das PNAD e MUNIC (IBGE), para levantamento da presença de conselhos participativos. Em acréscimo, replica-se a estratégia metodológica adotada em Gurza Lavalle, Voigt e Serafim (2016) que enfatiza a produção decisória dos conselhos (outputs) a fim de diagnosticar as decisões dos conselhos municipais ao longo do seu ciclo de vida, ampliando o foco analítico para a produção decisória relativa ao desastre do Rio Doce. Para a observação da atividade decisória dos conselhos e outros instrumentos de políticas públicas instituídos após o desastre foram levantados os atos administrativos publicados no Diário Oficial dos municípios de Linhares e Colatina e no estado do Espírito Santo no período entre 05/11/2015 e 05/11/2016 a partir da busca de palavras-chaves.

Ao passo que as análises qualitativas conduzem à compreensão dos Fóruns e Audiências Públicas, através da aplicação de entrevista em profundidade a 10 (dez) ativistas do Fórum Capixaba de Defesa do Rio Doce e do Movimento de Atingidos por Barragens (MAB), e da análise documental de atas do Fórum e vídeos das audiências públicas. As entrevistas em profundidade permitem o levantamento das ações dos movimentos sociais, organizações e atores da sociedade civil participantes dos fóruns e das audiências públicas, quanto aos seus repertórios de ação coletiva, enquadramentos interpretativos e redes de ativismo. Em complemento, a pesquisa documental em acervo produzido pelos atores sociais e órgãos públicos possibilita levantar os objetivos e a dinâmica de organização das coletividades que atuam nestas esferas, na defesa das comunidades atingidas pelo desastre. O processamento das informações das entrevistas e dos documentos foi auxiliado pelo software NVivo Pro 11.

Na próxima seção, discorremos sobre a produção decisória dos instrumentos de políticas públicas emergentes em diferentes arenas e níveis federativos. Em seguida, discutimos as formas de mobilização da sociedade civil representadas no Fórum Capixaba em Defesa do Rio Doce e seus fóruns locais, bem como o uso da Audiência Pública pelos atores sociais. Na seção final são apresentados os principais achados do estudo.

\section{1 "Mudança institucional": instrumentos de políticas públicas no contexto pós- desastre socioambiental do Rio Doce}

Esta sessão apresenta uma exploração analítica sobre a produção decisória de instrumentos de políticas públicas emergentes em diferentes arenas e níveis federativos, no contexto pós-desastre socioambiental do Rio Doce.

O conceito de instrumento utilizado é o da sociologia da ação pública francesa e é definido como um dispositivo tanto técnico como social, que organiza relações sociais específicas entre o Estado e os destinatários" das políticas e que, portanto, guarda "relações de poder e questões de legitimidade, politização ou dinâmicas de despolitização" (LASCOUMES, LE GALÈS, 2007, p. 04, tradução livre apud ZORZAL, CAYRES, SOUZA, 2017, p. 03). 
O objetivo inicial deste estudo foi replicar a mesma estratégia metodológica adotada em Gurza Lavalle, Voigt e Serafim (2016) que foca na produção decisória dos conselhos (outputs) e permite diagnosticar o que os conselhos fazem e quando o fazem, ou seja, que decisões tomam e em que momento de seu ciclo de vida (p. 611) para inferir sobre o que os conselhos estão fazendo no contexto do desastre. Os municípios de Linhares e Colatina foram escolhidos por constituírem, juntamente com Baixo Guandú, os primeiros municípios capixabas a serem reconhecidos como atingidos pelos rejeitos de lama5.

Para a observação da atividade decisória dos conselhos dos municípios de Linhares e Colatina foi utilizada como unidade de observação os atos administrativos emitidos e publicados no Diário Oficial dos municípios no período entre 05/11/2015 e 05/11/2016 ${ }^{6}$. A delimitação do período estudado equivaleu ao período de um ano imediatamente após o desastre7. Os dados foram coletados e organizados em arquivo Excel, seguindo a mesma metodologia do artigo citado, ou seja, por meio da procura nos arquivos digitalizados dos seguintes termos: conselho, resolução, orçamento participativo, governança participativa e participação social, acrescidos, para o propósito desta análise, dos seguintes termos: Comitês de Bacias e Rio Doce (estes dois últimos também pesquisados entre os atos emitidos pelo governo do estado do Espírito Santo). A nova combinação de palavras-chaves permitiu ampliar o escopo analítico para uma discussão mais ampla sobre a instituição de instrumentos de políticas públicas no contexto do desastre socioambiental do Rio Doce.

Ao analisar o conjunto da produção decisória após o desastre, por meio dos Diários Oficiais, constatou-se que não foi possível tecer conclusões substantivas sobre a produção decisória dos conselhos no município de Linhares, uma vez que encontramos apenas três resoluções referentes a produção decisória dos conselhos, que podem ser visualizadas no Quadro 1, além de uma resolução da AGERH que cita um dos Comitês de Bacias (Quadro 2) e 04 publicações referentes aos calendários de reuniões do CONDEMA, entre os 50 atos oficiais levantados a partir da busca de palavras-chave realizada sistematicamente no período em questão ${ }^{8}$. No caso de Colatina, conforme já mencionado, verificou-se que as publicações municipais são realizadas num diário oficial próprio, o qual se transformou em um consórcio a partir de 2015 que abrangeu outros municípios. Mas no de Linhares, ainda estamos em

${ }^{5}$ O município de Baixo Guandú será acrescido aos casos em artigo futuro.

6 Inicialmente utilizamos a publicação oficial do estado, disponível no sítio: http://ioes.dio.es.gov.br/portal/visualizacoes/diario_oficial.

7 Restringiu-se a este período, para os propósitos deste artigo, devido ao tempo de coleta e sistematização dos dados. No entanto, esta proposta faz parte de uma pesquisa mais ampla que está levantando os dados de um período maior, ou seja, três anos antes e depois do desastre.

${ }^{8}$ O município de Linhares tem uma população estimada de 169.048 pessoas, em 2017, segundo o IBGE, e conta com 15 conselhos, dos quais 4 foram criados antes do ano 2000 e os demais após esse ano. É importante ressaltar que, no ano de 2012, foi citada a não existência de Plano de Contingência ou Emergência para casos de desastres ambientais, dentro do Conselho de Meio ambiente. Com relação à efetividade desses Conselhos, verificou-se a quantidade de reuniões que os mesmos realizaram no ano de 2014. O Conselho de Alimentação Escolar não realizou nenhum encontro anual, mas os demais Conselhos realizaram pelo menos 5 encontros ao longo do ano.

${ }^{9}$ Após o levantamento de dados programado para os dois municípios, observou-se que no caso de Colatina as publicações se restringiam aos desdobramentos da Lei 8.666/1993, que dispõe sobre as normas e os contratos da administração pública, especialmente as licitações e seus desdobramentos (pregões eletrônicos, etc.). As publicações referentes aos demais atos oficiais estão disponíveis a 
processo de consulta aos órgãos locais e conferência com outras fontes de dados. Neste período, embora relativamente curto, além do rompimento da barragem que marca uma situação atípica, ocorreu um fato importante que foram as eleições municipais (onde o partido que governava PDT perdeu para o PMDB que retomou o poder), o que pode permitir possíveis variações nos padrões decisórios que somente serão verificados quando comparado com outros períodos.

Quadro 1: Síntese das resoluções dos conselhos

\begin{tabular}{|c|c|l|l|l|l|}
\hline $\mathbf{N}^{\circ}$. & \multicolumn{1}{|c|}{ Data } & \multicolumn{1}{|c|}{ Resolução } & \multicolumn{1}{|c|}{ Descrição } & \multicolumn{1}{c|}{ Âmbito } & \multicolumn{1}{|c|}{ Tipo } \\
\hline 01 & $01 / 12 / 2015$ & $\begin{array}{l}\mathrm{N}^{\circ} \text { 002/2015 } \\
\text { COMDEMA }\end{array}$ & $\begin{array}{l}\text { Aprova o Regimento de Uso do Fundo } \\
\text { Municipal de Defesa do Meio Ambiente - } \\
\text { FUMDEMA, e dá outras providências. }\end{array}$ & Municipal & Regulação \\
\hline 02 & $03 / 06 / 2016$ & $\begin{array}{l}\text { Decreto No. } \\
697 / 2016\end{array}$ & $\begin{array}{l}\text { Dispõe sobre nomeação dos membros } \\
\text { que irão compor o Conselho Municipal } \\
\text { de Cultura - COMCULT. }\end{array}$ & Municipal & Regulação/Nomeação \\
\hline 03 & $07 / 10 / 2016$ & $\begin{array}{l}\text { Resolução No } \\
119 / 2013 / \text { CMS }\end{array}$ & $\begin{array}{l}\text { Aprova a eleição de comissões } \\
\text { permanentes do Conselho Municipal de } \\
\text { Saúde de Linhares. }\end{array}$ & Municipal & Deliberação \\
\hline
\end{tabular}

Fonte: Elaboração própria a partir de informações coletadas no D.O. do Estado do ES (11/2015 a 11/2016).

Ao analisar o conjunto da produção decisória após o desastre, por meio dos Diários Oficiais, destacam-se um conjunto de instrumentos (Portaria, Decreto, Ato Normativo, Resolução e Lei) produzidos por atores estatais em diferentes arenas e níveis federativos (Executivo, legislativo, estadual, municipal, Procuradoria Geral da Justiça, Defensoria pública, etc.) que pode ser visualizado no Quadro $2^{10}$.

partir de 01/01/2015 no sítio do Diário Municipal, conforme Lei No. 6.903/2014. Portanto, as informações referentes ao município de Colatina estão sendo coletadas novamente e não serão apresentadas neste artigo que se restringiu ao caso do município de Linhares, assim como as outras arenas (Executivo, Legislativo, Judiciário representado pela Procuradoria Geral do Estado e Defensoria do Estado) e esferas de governo que aparecem nos documentos analisados (municipal e estadual).

${ }^{10}$ Entre os 50 atos oficiais inicialmente coletados, exceto os 03 relativos aos Conselhos e os 04 que somente informam o calendário de reuniões, descartamos do quadro aqueles que se referiam aos temas que não se adequaram aos propósitos da coleta. Exemplo: licitação para locação de espaço físico, contratos, compra de insumos relacionadas em algum grau com algum tipo de conselho, etc. 
Quadro 2. Síntese dos instrumentos selecionados

\begin{tabular}{|c|c|c|c|c|c|}
\hline $\mathrm{N}^{\circ}$. & Data & Instrumento & Descrição & Âmbito & Observações \\
\hline 01 & $11 / 11 / 2015$ & $\begin{array}{c}\text { Portaria } n^{\circ} . \\
8454\end{array}$ & $\begin{array}{c}\text { Institui a "Força Tarefa Rio } \\
\text { Doce" (FTRD) no estado do } \\
\text { ES. }\end{array}$ & PGJ & $\begin{array}{l}\text { Formada por } \\
\text { promotores de } \\
\text { justiça com } \\
\text { atribuição } \\
\text { ambiental dos } \\
\text { municípios } \\
\text { capixabas } \\
\text { impactados; com } \\
\text { a função de } \\
\text { propor ações, } \\
\text { elaboração de } \\
\text { TTACs, } \\
\text { notificações, } \\
\text { manifestações, } \\
\text { etc. }\end{array}$ \\
\hline 02 & $16 / 11 / 2015$ & $\begin{array}{c}\text { Decreto } n^{\circ} . \\
3896-R\end{array}$ & $\begin{array}{l}\text { Institui o Comitê Gestor da } \\
\text { Crise Ambiental na Bacia } \\
\text { do Rio Doce CGCA/Rio } \\
\text { Doce, vinculado à } \\
\text { Secretaria Estadual de } \\
\text { Meio Ambiente e Recursos } \\
\text { Hídricos - SEAMA. }\end{array}$ & $\begin{array}{l}\text { Executivo } \\
\text { (estadual) }\end{array}$ & $\begin{array}{l}\text { Institui o Comitê } \\
\text { com funções } \\
\text { gerenciais para } \\
\text { atuar em regime } \\
\text { de cooperação } \\
\text { com outros } \\
\text { órgãos e } \\
\text { entidades da } \\
\text { administração } \\
\text { pública, com um } \\
\text { representante do } \\
\text { Comitê da Bacia } \\
\text { Hidrográfica do } \\
\text { Rio e um } \\
\text { representante do } \\
\text { conjunto dos } \\
\text { Comitês } \\
\text { capixabas. }\end{array}$ \\
\hline 03 & $16 / 11 / 2015$ & $\begin{array}{c}\text { Ato } \\
\text { Normativo } \\
\text { DPES n.003 }\end{array}$ & $\begin{array}{l}\text { Institui o Grupo de } \\
\text { Trabalho da Defensoria } \\
\text { Pública do Estado do ES. }\end{array}$ & $\begin{array}{c}\text { Defensoria } \\
\text { Pública } \\
\text { (estadual) }\end{array}$ & $\begin{array}{c}\text { Função de prestar } \\
\text { assistência jurídica } \\
\text { integral e } \\
\text { promoção de } \\
\text { direitos humanos } \\
\text { aos impactados } \\
\text { direta e } \\
\text { indiretamente. }\end{array}$ \\
\hline 04 & $16 / 11 / 2015$ & $\begin{array}{l}\text { Resolução } \\
\text { AGERH } \\
014 / 2015\end{array}$ & $\begin{array}{c}\text { Dispõe sobre exceção, } \\
\text { autorizando a empresa } \\
\text { SAMARCO S.A. a perfurar } \\
\text { poço profundo no } \\
\text { município de Baixo Guandu } \\
\text { e Colatina e dá outras } \\
\text { providências }\end{array}$ & AGERH & $\begin{array}{c}\text { Medidas de } \\
\text { emergência para } \\
\text { abastecimento de } \\
\text { água. }\end{array}$ \\
\hline 05 & $17 / 11 / 2015$ & $\begin{array}{c}\text { Resolução } \\
\text { AGERH } \\
015 / 2015\end{array}$ & $\begin{array}{c}\text { Dispõe sobre a inclusão } \\
\text { dos Municípios de Colatina, } \\
\text { Pancas e Marilândia na } \\
\text { qualidade de municípios }\end{array}$ & AGERH & $\begin{array}{l}\text { Municípios em } \\
\text { situação crítica } \\
\text { quanto ao }\end{array}$ \\
\hline
\end{tabular}




\begin{tabular}{|c|c|c|c|c|c|}
\hline$N^{\circ}$. & Data & Instrumento & Descrição & Âmbito & Observações \\
\hline & & & $\begin{array}{c}\text { em situação extremamente } \\
\text { crítico. }\end{array}$ & & $\begin{array}{c}\text { abastecimento de } \\
\text { água. }\end{array}$ \\
\hline
\end{tabular}

\begin{tabular}{|c|c|c|c|c|c|}
\hline $\mathbf{N}^{\circ}$. & Data & Instrumento & Descrição & Âmbito & Observações \\
\hline 06 & $23 / 11 / 2015$ & $\begin{array}{l}\text { Portaria } \\
\text { SEAMA/ } \\
\text { IEMA/AGERH } \\
\mathrm{n}^{\circ} .004-\mathrm{R}\end{array}$ & $\begin{array}{l}\text { Declara situação de } \\
\text { Emergência Ambiental na } \\
\text { região da Bacia } \\
\text { Hidrográfica do Rio Doce, } \\
\text { Estado do ES. }\end{array}$ & $\begin{array}{c}\text { SEAMA/ } \\
\text { IEMA/ } \\
\text { AGERH }\end{array}$ & $\begin{array}{l}\text { Declaração de } \\
\text { situação de } \\
\text { emergência } \\
\text { ambiental nos } \\
\text { municípios } \\
\text { margeados pelo } \\
\text { Rio Doce. }\end{array}$ \\
\hline 07 & $23 / 11 / 2015$ & $\begin{array}{l}\text { Portaria } \\
\text { SEAMA/ } \\
\text { IEMA/AGERH } \\
\mathrm{n}^{\circ} .16-\mathrm{S}\end{array}$ & $\begin{array}{l}\text { Instituir o Grupo Técnico } \\
\text { de Enfrentamento da Crise } \\
\text { Ambiental no Rio Doce - } \\
\text { GTECAD; }\end{array}$ & $\begin{array}{c}\text { SEAMA/ } \\
\text { IEMA/ } \\
\text { AGERH }\end{array}$ & $\begin{array}{l}\text { Ligado ao Comitê } \\
\text { Gestor da Crise } \\
\text { Ambiental na } \\
\text { Bacia do Rio Doce } \\
\text { - CGCA/Rio Doce, } \\
\text { atua em três } \\
\text { níveis: I - Nível de } \\
\text { Coordenação; I - } \\
\text { Nível de } \\
\text { Assessoria; III - } \\
\text { Nível Técnico. }\end{array}$ \\
\hline 08 & $25 / 11 / 2015$ & $\begin{array}{c}\text { Portaria } \mathrm{n}^{\circ} \\
8.838\end{array}$ & $\begin{array}{c}\text { Designa o Procurador de } \\
\text { Justiça Dr. Alexandre José } \\
\text { Guimarães para exercer a } \\
\text { função de adjunto nos três } \\
\text { municípios no que se } \\
\text { refere aos assuntos da } \\
\text { tragédia e para colaborar } \\
\text { com a FTRD. }\end{array}$ & PGJ & $\begin{array}{l}\text { Nomeação de PG } \\
\text { especifico para o } \\
\text { caso do desastre } \\
\text { do Rio Doce. }\end{array}$ \\
\hline 09 & $27 / 11 / 2015$ & $\begin{array}{c}\text { Lei N N }{ }^{\circ} \\
3.542\end{array}$ & $\begin{array}{l}\text { Cria o Fundo Municipal de } \\
\text { Proteção e Defesa Civil - } \\
\text { FUNMPDEC do Município } \\
\text { de Linhares, institui o } \\
\text { Conselho Gestor, e dá } \\
\text { outras providências. }\end{array}$ & $\begin{array}{l}\text { Executivo } \\
\text { (municipal) }\end{array}$ & $\begin{array}{l}\text { Criação de fundo } \\
\text { e respectivo } \\
\text { conselho } \\
\text { vinculado, com } \\
\text { representantes do } \\
\text { Estado e da } \\
\text { sociedade civil. }\end{array}$ \\
\hline 10 & $30 / 11 / 2015$ & $\begin{array}{c}\text { Resolução } \\
\text { AGERH } \\
017 / 2015\end{array}$ & $\begin{array}{c}\text { Dispõe sobre a autorização } \\
\text { para a empresa Samarco } \\
\text { Mineração S.A a perfurar } \\
\text { poços profundos nos } \\
\text { municípios de Baixo } \\
\text { Guandu e Colatina e dá } \\
\text { outras providências }\end{array}$ & AGERH & $\begin{array}{c}\text { Medidas de } \\
\text { emergência para } \\
\text { abastecimento de } \\
\text { água. }\end{array}$ \\
\hline 11 & $09 / 12 / 2015$ & $\begin{array}{c}\text { Resolução } \\
\text { AGERH } \\
018 / 2015\end{array}$ & $\begin{array}{c}\text { Dispõe sobre a exclusão da } \\
\text { bacia do Rio São João } \\
\text { Grande das restrições } \\
\text { constantes das Resoluções } \\
\text { AGERH 005/2015, 006/2015 } \\
\text { e 015/2015 visando priorizar } \\
\text { a dessedentação humana } \\
\text { no contexto do Cenário de } \\
\text { Alerta vigente em todas as }\end{array}$ & AGERH & $\begin{array}{c}\text { Medidas } \\
\text { regulatórias } \\
\text { voltadas ao } \\
\text { abastecimento de } \\
\text { água. }\end{array}$ \\
\hline
\end{tabular}




\begin{tabular}{|c|c|c|c|c|c|}
\hline $\mathbf{N}^{\circ}$. & Data & Instrumento & Descrição & Âmbito & Observações \\
\hline & & & $\begin{array}{c}\text { bacias hidrográficas de rios } \\
\text { de domínio do Estado do } \\
\text { Espírito Santo e, dá outras } \\
\text { providências. }\end{array}$ & & \\
\hline
\end{tabular}

\begin{tabular}{|c|c|c|c|c|c|}
\hline $\mathrm{N}^{\circ}$. & Data & Instrumento & Descrição & Âmbito & Observações \\
\hline 12 & $10 / 12 / 2015$ & $\begin{array}{l}\text { Resolução } \\
\text { AGERH } \\
019 / 2015\end{array}$ & $\begin{array}{c}\text { Dispõe sobre a } \\
\text { homologação do Acordo } \\
\text { de Cooperação } \\
\text { Comunitária da Bacia do } \\
\text { Rio São José (ACC). }\end{array}$ & AGERH & $\begin{array}{c}\text { Acordo de } \\
\text { cooperação } \\
\text { Comunitária o } \\
\text { qual exclui da } \\
\text { vigência da } \\
\text { Resolução AGERH } \\
\text { 006/2015 a } \\
\text { totalidade do } \\
\text { município de São } \\
\text { Gabriel da Palha. }\end{array}$ \\
\hline 13 & $04 / 11 / 2015$ & $\begin{array}{l}\text { Processo } N^{\circ} . \\
001084 / 2015\end{array}$ & Dispensa de licitação SAAE. & $\begin{array}{l}\text { Executivo/ } \\
\text { Autarquia } \\
\text { (municipal) }\end{array}$ & $\begin{array}{c}\text { Medidas } \\
\text { regulatórias } \\
\text { voltadas ao } \\
\text { abastecimento de } \\
\text { água. }\end{array}$ \\
\hline 14 & $19 / 01 / 2016$ & $\begin{array}{l}\text { Resolução } \\
\text { AGERH } \\
022 / 2016\end{array}$ & $\begin{array}{c}\text { Dispõe sobre a quarta } \\
\text { prorrogação das } \\
\text { Resoluções AGERH } \\
\text { 005/2015 e 006/2015, frente } \\
\text { ao prolongamento da } \\
\text { Escassez Hídrica em rios de } \\
\text { domínio do Estado do } \\
\text { Espírito Santo e dá outras } \\
\text { providências. }\end{array}$ & AGERH & $\begin{array}{c}\text { Medidas } \\
\text { regulatórias } \\
\text { voltadas ao } \\
\text { abastecimento de } \\
\text { água. }\end{array}$ \\
\hline 15 & $19 / 01 / 2016$ & $\begin{array}{c}\text { Resolução } \\
\text { AGERH } \\
023 / 2016\end{array}$ & $\begin{array}{c}\text { Dispõe sobre a exclusão da } \\
\text { bacia hidrográfica do Rio } \\
\text { Pancas do quadro de locais } \\
\text { de situação extremamente } \\
\text { crítica, alterando o Quadro } \\
\text { que compõe o Anexo } \\
\text { Único da Resolução AGERH } \\
N^{\circ} 006 / 2015 .\end{array}$ & AGERH & $\begin{array}{c}\text { Medidas } \\
\text { regulatórias } \\
\text { voltadas ao } \\
\text { abastecimento de } \\
\text { água. }\end{array}$ \\
\hline 16 & $26 / 01 / 2016$ & $\begin{array}{l}\text { Processo } \\
\text { Dispensa de } \\
\text { licitação }\end{array}$ & $\begin{array}{c}\text { Contratação de empresa } \\
\text { especializada em caráter } \\
\text { (Art. 24, inciso IV, da Lei nº } \\
\text { 8.666/93), para a } \\
\text { realização de serviço de } \\
\text { desmobilização e } \\
\text { mobilização para novo } \\
\text { local, com readequação da } \\
\text { Tomada de Água, em } \\
\text { virtude do desastre } \\
\text { ocorrido. }\end{array}$ & $\begin{array}{l}\text { Executivo/ } \\
\text { Autarquia } \\
\text { (municipal) }\end{array}$ & $\begin{array}{c}\text { Medidas } \\
\text { regulatórias } \\
\text { (dispensa de } \\
\text { licitação) voltadas } \\
\text { ao abastecimento } \\
\text { de água. }\end{array}$ \\
\hline 17 & $18 / 02 / 2016$ & $\begin{array}{c}\text { Lei } \\
\mathrm{N}^{\circ} .3568 / 2016\end{array}$ & $\begin{array}{l}\text { Dispõe sobre a criação do } \\
\text { Programa Municipal de } \\
\text { recuperação das margens } \\
\text { do Rio Doce, Rio Pequeno }\end{array}$ & $\begin{array}{l}\text { Legislativo } \\
\text { (municipal) }\end{array}$ & $\begin{array}{l}\text { Criação de } \\
\text { Legislação } \\
\text { municipal visando } \\
\text { recuperação das }\end{array}$ \\
\hline
\end{tabular}




\begin{tabular}{|c|c|c|c|c|c|}
\hline $\mathbf{N}^{\circ}$. & Data & Instrumento & Descrição & Âmbito & Observações \\
\hline & & & e demais rios deste & & margens do Rio \\
& & & município, com espécies & & Doce. \\
& & & arbóreas e recuperação & & \\
& & & das matas ciliares como & & \\
& & & compensação ambiental, e & & \\
& & & dá outras providências & & \\
\hline
\end{tabular}

\begin{tabular}{|c|c|c|c|c|c|}
\hline $\mathbf{N}^{\circ}$. & Data & Instrumento & Descrição & Âmbito & Observações \\
\hline 18 & $15 / 03 / 2016$ & $\begin{array}{c}\text { Processo No: } \\
1418 / 2016\end{array}$ & $\begin{array}{c}\text { Ratificação referente a } \\
\text { dispensa de licitação para } \\
\text { fornecer marmitex } \\
\text { destinado a atender } \\
\text { desabrigadas sucedidas de } \\
\text { desastres naturais no } \\
\text { Município (nível do Rio } \\
\text { Doce ultrapassou a cota de } \\
\text { inundação), pelo período } \\
\text { de } 07 \text { (sete) dias, no valor } \\
\text { estimado de R\$ } 14.820,00 \\
\text { (quatorze mil, oitocentos e } \\
\text { vinte reais). }\end{array}$ & $\begin{array}{l}\text { Executivo } \\
\text { (municipal) }\end{array}$ & $\begin{array}{c}\text { Medidas } \\
\text { regulatórias } \\
\text { (dispensa de } \\
\text { licitação) voltadas } \\
\text { ao atendimento } \\
\text { aos desabrigados. }\end{array}$ \\
\hline 19 & $08 / 04 / 2016$ & $\begin{array}{l}\text { Resolução } \\
\text { Nº.001/2016 }^{\circ}\end{array}$ & $\begin{array}{l}\text { Instauração da Comissão } \\
\text { Parlamentar de Inquérito } \\
\text { constituída através da } \\
\text { Resolução n.003/2015 } \\
\text { datada de } 21 \text { de outubro de } \\
2015 \text { para apurar fatos } \\
\text { relacionados ao canal de } \\
\text { transposição das águas do } \\
\text { Rio Doce para o Município } \\
\text { de Aracruz-ES. }\end{array}$ & $\begin{array}{l}\text { Legislativo } \\
\text { (municipal) }\end{array}$ & $\begin{array}{c}\text { Instaura CPI } \\
\text { Legislativo ligada } \\
\text { ao Rio Doce. }\end{array}$ \\
\hline 20 & $02 / 06 / 2016$ & $\begin{array}{c}\text { Resolução } \\
\text { AGERH } \\
034 / 2016\end{array}$ & $\begin{array}{c}\text { Dispõe sobre a inclusão de } \\
\text { municípios no quadro do } \\
\text { anexo único da Resolução } \\
\text { AGERH o06/15; homologa } \\
\text { acordos de cooperação } \\
\text { comunitária e suspende o } \\
\text { acordo de cooperação } \\
\text { comunitária dos municípios } \\
\text { de Águia e São Gabriel da } \\
\text { Palha. }\end{array}$ & AGERH & $\begin{array}{l}\text { Mudanças nos } \\
\text { acordos de } \\
\text { cooperação } \\
\text { comunitária } \\
\text { (regulação). }\end{array}$ \\
\hline 21 & $09 / 06 / 2016$ & $\begin{array}{c}\text { Resolução no } \\
003 / 2016\end{array}$ & $\begin{array}{c}\text { Fica constituída a Comissão } \\
\text { Parlamentar de Inquérito, } \\
\text { com objetivo de investigar } \\
\text { fatos relevantes à } \\
\text { apuração da má gestão } \\
\text { administrativa e financeira } \\
\text { do SAAE. }\end{array}$ & $\begin{array}{l}\text { Legislativo } \\
\text { (municipal) }\end{array}$ & $\begin{array}{l}\text { Instaura CPI da } \\
\text { gestão do SAAE. }\end{array}$ \\
\hline
\end{tabular}




\begin{tabular}{|c|c|c|c|c|c|}
\hline$N^{\circ}$. & Data & Instrumento & Descrição & Âmbito & Observações \\
\hline 22 & $22 / 06 / 2016$ & $\begin{array}{c}\text { Resolução } n^{\circ} \\
004 / 2016\end{array}$ & $\begin{array}{c}\text { Dispõe sobre a composição } \\
\text { da CPI do SAAE. }\end{array}$ & $\begin{array}{c}\text { Legislativo } \\
\text { (municipal) }\end{array}$ & $\begin{array}{c}\text { CPI da gestão do } \\
\text { SAAE. }\end{array}$ \\
\hline 23 & $01 / 07 / 2016$ & $\begin{array}{c}\text { Resolução } \\
\mathrm{N}^{\circ} 005 / 2016\end{array}$ & $\begin{array}{c}\text { Dispõe sobre a composição } \\
\text { da CPI do SAAE. }\end{array}$ & $\begin{array}{c}\text { Legislativo } \\
\text { (municipal) }\end{array}$ & $\begin{array}{c}\text { CPI da gestão do } \\
\text { SAAE. }\end{array}$ \\
\hline 24 & $07 / 07 / 2016$ & $\begin{array}{c}\text { Resolução } \\
\mathrm{N}^{\circ} 006 / 2016\end{array}$ & $\begin{array}{c}\text { Dispõe sobre a composição } \\
\text { da CPI do SAAE. }\end{array}$ & $\begin{array}{c}\text { Legislativo } \\
\text { (municipal) }\end{array}$ & $\begin{array}{c}\text { CPI da gestão do } \\
\text { SAAE. }\end{array}$ \\
\hline
\end{tabular}

Fonte: Elaboração própria a partir de informações coletadas no D.O. do Estado do ES (11/2015 a 11/2016).

Embora a pesquisa seja inicial foi possível mapear alguns importantes padrões de relação emergentes no contexto do desastre socioambiental no Rio Doce tendo em vista a produção de instrumentos de políticas públicas orientados pelos interesses e aspirações dos atores envolvidos nas disputas contenciosas (HALPERN, LE GALÈS, 2011; LASCOUMES, LE GALÈS, 2007).

Os padrões de relação encontrados foram inspirados na tipologia desenvolvida por Lascoumes e Le Gales (2007) e adaptados ao contexto estudado ${ }^{11}$, conforme melhor explicitado no Quadro 3:

\section{Quadro 3. Modelo de análise dos instrumentos de políticas públicas}

\begin{tabular}{|c|c|c|}
\hline $\begin{array}{l}\text { Níveis de } \\
\text { análise* }\end{array}$ & Descrição dos mecanismos & Tipologia (instrumentos) \\
\hline Instrumento & $\begin{array}{c}\text { Função de mobilização de distintos recursos } \\
\text { organizacionais por autoridades públicas em } \\
\text { diferentes níveis (municipal, estadual e federal). }\end{array}$ & \multirow{2}{*}{$\begin{array}{c}\text { Representativo } \\
\text { (Executivo, legislativo, } \\
\text { sistema de justiça e } \\
\text { sociedade civil) }\end{array}$} \\
\hline $\begin{array}{l}\text { Relação } \\
\text { política }\end{array}$ & $\begin{array}{c}\text { As relações entre os atores politicos, os atores } \\
\text { sociais e os mecanismos competitivos } \\
\text { (mercado). }\end{array}$ & \\
\hline Legitimidade & $\begin{array}{c}\text { Tipos: interesses dos representantes eleitos, } \\
\text { benefícios para a sociedade em geral } \\
\text { (negociados ou não democraticamente), } \\
\text { critérios técnicos de eficiência econômica ou de } \\
\text { accontability e a pressão de mecanismos de } \\
\text { mercado. }\end{array}$ & $\begin{array}{c}\text { Regulatório } \\
\text { (Executivo e legislativo) } \\
\text { Fiscalizatório } \\
\text { (Executivo e legislativo) }\end{array}$ \\
\hline
\end{tabular}

Fonte: Elaboração própria. * Níveis de análise propostos Lascoumes e Le Gales (2007, p. 12), adaptados para o caso estudado.

Conforme visualizado no Quadro 3, os instrumentos analisados se enquadram em um ou mais dos três diferentes tipos: 1. Representativo; 2. Regulatório; e 3. Fiscalizatório, construídos a partir da variação entre os elementos elencados nos níveis de análise: instrumento, relação política e legitimidade.

Em primeiro lugar destaca-se o aparecimento de novas instituições que mobilizam diferentes recursos organizacionais (gestão, técnico, financeiro e participativo) em diferentes arenas: Executivo, legislativo, sistema de justiça e

\footnotetext{
${ }^{11}$ Os autores definem instrumento como uma tecnologia de governo que varia de acordo com seus vários formatos e distinguem cinco principais modelos de análise. Essa tipologia parte de um modelo desenvolvido por Hood, baseado na mobilização de recursos por autoridades públicas, e avança incorporando tipos de relações políticas e tipos de legitimidade que tais relações pressupõem (LASCOUMES; LE GALES, 2007, p. 12).
} 
distintas esferas: estadual e municipal, com variados tipos de relações políticas e graus de legitimidade.

Estamos chamando de instrumentos representativos as novas e variadas formas de representação instituídas por diferentes atores políticos tanto no âmbito estadual quanto municipal, tais como: 1. a Força Tarefa Rio Doce (FTRD) representando o Ministério Público, através dos promotores de justiça com atribuição ambiental dos municípios capixabas atingidos, e intermediando as relações entre o Estado, a população atingida e as empresas responsáveis; 2. o Comitê Gestor da Crise Ambiental da Bacia do Rio Doce (CGCA/Rio Doce) formados por representantes do Executivo e um representante do Comitê da Bacia Hidrográfica do Rio Doce e um do conjunto dos Comitês capixabas, tem funções gerenciais para intermediar as relações em regime de cooperação com outros órgãos e entidades da administração pública; 3. O Grupo de Trabalho da Defensoria do Estado do ES: com representantes deste órgão com função de intermediar os interesses dos atingidos direta e indiretamente pelo desastre através da assistência jurídica integral e promoção dos direitos humanos; 4. o Grupo Técnico de Enfrentamento da Crise Ambiental no Rio Doce (GTECAD): ligado ao CGCA/Rio Doce, com atribuições técnicas em três níveis: coordenação, assessoria e técnico; e 5. 0 Conselho Gestor do Fundo Municipal de Proteção e Defesa Civil vinculado ao FUNMPDEC - Fundo Municipal de Proteção e Defesa Civil, composto por cinco membros, sendo o presidente indicado pelo Chefe do Poder Executivo, 02 (dois) escolhidos dentre os membros que compõem a Coordenadoria Municipal de Proteção e Defesa Civil - COMPDEC e 02 (dois) indicados pela sociedade civil.

O grupo de instrumentos regulatórios compreende especialmente o conjunto de medidas de emergência tomadas para abastecimento de água, assim como novos acordos e legislações que foram produzidas em detrimento do desastre. Podemos citar, entre as várias iniciativas dos diversos órgãos e entes considerados, as Portarias SEAMA/IEMA/AGERH No. 004-R e 16-S que declaram situação crítica quanto ao abastecimento de água e situação de emergência ambiental nos municípios margeados pelo Rio Doce, que terão impacto por exemplo em outras resoluções (autorizando a empresa Samarco S.A. a perfurar poços nos municípios atingidos) e alterações de normas como a dispensa de licitação para medidas voltada ao abastecimento de água e a assistência a população desabrigada. A criação do Programa Municipal de Recuperação das margens do Rio Doce, Rio Pequeno e demais Rios (PMRM- Rio Doce e outros), por exemplo, que constitui uma iniciativa do legislativo municipal visando recuperação das margens do Rio Doce. E, por último, a criação do Fundo Municipal de Proteção e Defesa Civil, pelo Executivo Municipal, administrado por um Conselho Gestor, visando captar, controlar e aplicar recursos financeiros, de modo a garantir a execução de ações de prevenção e preparação em áreas de risco de desastres, de resposta e de recuperação em áreas atingidas por desastres.

Por fim, os instrumentos de fiscalização abarcam as medidas do legislativo municipal (instauração de CPIs), além do conselho gestor criado pelo Executivo vinculado ao FUNMPDEC que também pode se enquadrar aqui.

Nota-se que esses instrumentos levantados são mecanismos que estão orientando as relações entre o governo, a sociedade civil e os interesses de mercado, representados pelas empresas responsabilizadas pelo desastre, por meio de 
dispositivos de representação que incluem mais componentes técnicos do que componentes sociais. Em outras palavras, esses instrumentos revelam as diferentes capacidades de ação dos atores políticos institucionalizados e organizam as relações de poder de um determinado modo.

No entanto, ainda é preciso levantar os desdobramentos dessas instituições e os potenciais conflitos entre os atores que as ocupam para entender tanto a escolha desses instrumentos em detrimentos de outros quanto os potenciais efeitos nos atores envolvidos independentemente dos seus objetivos. O próximo passo dessa pesquisa vai focar nas redes de relações estabelecidas entre essas instituições, os atores que as ocupam, assim como os partidos políticos e a sua composição de forças no Executivo e Legislativo para desvendar algumas dessas questões. 


\subsection{Mudanças organizacionais na sociedade civil: mobilizações, fóruns e audiências públicas no contexto pós-desastre no Rio Doce}

Nesta seção, buscamos demonstrar que o desastre socioambiental no Rio Doce produziu mudanças nas formas de ação coletiva e mobilização social através da emergência de movimentos sociais, ativistas e formatos de organização popular. As trajetórias de lutas sociais se desenvolveram nos territórios capixabas desde a chegada da lama de rejeitos, mobilizando atingidos, atores sociais e instituições apoiadoras em prol da reparação dos múltiplos danos e da reconstrução dos modos de vida das populações afetadas. Essas se estabeleceram em face de um diagnóstico duplo: de um lado, as percepções individuais e coletivas dos impactos ambientais, sociais, econômicos, culturais e simbólicos decorrentes do "desastre-crime", assim denominado pelos atores mobilizados; de outro, a percepção social de inação dos governos municipais e estaduais e de autorregulação das consequências do desastre pelas empresas Samarco-Vale-BHP responsabilizadas pelo crime. Diante da injustiça ambiental e social assim enquadrada, atingidos, atores e organizações mobilizadas reivindicaram e propuseram reparações judiciais e políticas de reconstrução que remetem aos setores de assistência social, saneamento, saúde, segurança alimentar, meio ambiente, desenvolvimento econômico e direitos humanos, bem como reivindicam a participação dos atingidos nas decisões públicas e a assessoria jurídica à população afetada. Suas motivações para as lutas sociais são múltiplas, desde o sentimento de injustiça pelas perdas humanas, materiais, culturais e simbólicas até as oportunidades de reconhecimento e reparação dos direitos e de reestruturação dos modos de vida e de organização social, as últimas expressas no "efeito demonstração" dos resultados da ação coletiva convertidas em conquistas concretas.

Os grupos sociais mobilizados em prol do reconhecimento dos atingidos e da recuperação do meio ambiente afetado são compostos por atores coletivos e individuais, associações, organizações e movimentos sociais, seja preexistentes seja emergentes após o desastre socioambiental. Dos segmentos previamente existentes nos territórios observam-se diversas associações civis (pescadores, moradores, artesãos, culturais, esportivas), movimentos sociais (direitos humanos, ambientalistas e agrícolas, como o Movimento de Pequenos Agricultores-MPA e o Movimento dos Trabalhadores Sem Terra-MST), sindicatos (trabalhadores rurais, bancários, comerciários, industriais, servidores públicos) e associações religiosas (Comissão Justiça e Paz-CJP, Cáritas, pastorais, entre outras). Formatos institucionalizados de participação também são existentes nos municípios atingidos, como orçamento participativo, conselhos gestores, conferências de políticas setoriais e comitês de bacia hidrográfica, embora essas apresentem poucas iniciativas relativas ao desastre.

Das modalidades emergentes de ação coletiva, o rompimento da barragem e a chegada da lama de rejeitos no território capixaba impulsionaram a criação de fóruns da sociedade civil, em nível estadual e local, a exemplo do Fórum Capixaba em Defesa do Rio Doce, do Fórum SOS Rio Doce, do Fórum Foz Norte e Fórum Foz Sul. Considerado uma inovação organizacional, o Fórum Capixaba em Defesa do Rio Doce 
(FCDRD) ${ }^{12}$ surgiu com o objetivo de monitorar as ações de responsabilização da empresa causadora do desastre, cobrar a adoção de medidas reparatórias dos impactos ambientais e humanos, cobrar a adoção de medidas para prevenção de novos desastres, e promover a articulação entre movimentos, organizações sociais e atingidos a fim de tornar pública a causa. O FCDRD foi criado por organizações do Movimento Estadual de Direitos Humanos (MEDH), do Movimento Nacional de Direitos Humanos (MNDH) e pela Comissão Justiça e Paz (CJP) da Igreja Católica, congregando diversas organizações e entidade civis. ${ }^{13} \mathrm{~A}$ análise destaca o FCDRD como um espaço de articulação de movimentos sociais e organizações da sociedade civil, de mobilização dos atingidos e de denúncias do desastre, em nível nacional e internacional. A estratégia de articulação do FCDRD com os atingidos levou à sua descentralização e à criação de Fóruns Locais nas áreas afetadas no Espírito Santo. Sua dinâmica organizacional é caracteriza por coordenação ampliada, composta por comissões especializadas, grupos de trabalho temáticos ${ }^{14}$ e plenárias gerais, além dos fóruns locais. Atualmente possui uma rotina de reuniões mensal, tendo sido semanal sua frequência no primeiro ano do desastre, período que contabilizou 49 reuniões de novembro de 2015 a dezembro de 2016 (CARLOS, MARTINS, 2017). Em sua estrutura organizacional, são quatro os fóruns locais estabelecidos: Fórum SOS Rio Doce que abrange os atingidos dos municípios de Colatina e Baixo Guandu, Fórum Foz Norte que congrega as localidades da foz norte do Rio Doce e o município de São Mateus, e o Fórum Foz Sul que abrange localidades da foz sul e município de Aracruz (CARLOS, GOMES, 2018).

Os repertórios de ação coletiva do Fórum consistem na realização de passeatas, marchas, dramatizações, atos públicos, audiências públicas, e a formalização de denúncias às autoridades incluso às organizações internacionais de direitos humanos como a Organização dos Estados Americanos-OEA e a Organização das Nações Unidas-ONU. Os repertórios de ação coletiva consistem em "(...) conjuntos de performances reivindicatórias, historicamente criada, limitada e familiar, que circunscrevem geralmente as formas pelas quais as pessoas se engajam na política contenciosa" (TILLY, 2008, p. vii). No contexto do desastre, estas ações de contestação são orientadas pelos enquadramentos interpretativos dos ativistas e dos atingidos, ou seja, suas percepções dos impactos socioambientais, das causas e dos oponentes, das pautas de reivindicação e proposições, sintetizadas no frame desastre-crime.

\footnotetext{
12 Fundado no dia 16 de novembro de 2015, em Vitória-ES, por meio de manifesto denominado “Manifesto de Criação do Fórum Capixaba de Entidades em Defesa do Rio Doce", assinado por 72 organizações sociais, atualmente com 58 entidades participantes.

${ }^{13}$ No seu manifesto reuniu diversos setores sociais, sendo: movimento estadual e nacional de direitos humanos, conselho estadual de direitos humanos, conselho de segurança alimentar e nutricional, conselhos das Igrejas Cristãs, conselhos, comissões e pastorais da Igreja Católica, Cáritas, fórum estadual da juventude negra, Ordem dos Advogados do Brasil, movimento estadual e municipais de mulheres e de mulheres negras, união geral e central única dos trabalhadores, sindicatos trabalhistas, transparência capixaba, movimento de pequenos agricultores, movimento dos trabalhadores sem terra, federação das associações e movimentos populares, dentre outros.

14 São quatro as comissões permanentes: comissão de articulação, comissão de documentação, comunicação de comunicação e comissão de mobilização. Ao passo que os grupos de trabalho são temporários e formados espontaneamente.
} 
As ações de internacionalização da causa ambiental e humanitária foram forjadas já no mês subsequente ao desastre, em 03 de dezembro de 2015, quando o FCDRD impetrou denúncia à ONU em Carta Aberta, apelando para uma investigação independente do desastre. O FCDRD apresentou nova denúncia aos organismos internacionais de direitos humanos, em 01 de abril de 2016, na OEA, com pronunciamento de ativista do movimento de direitos humanos do Espírito Santo, em Washington, contextualizando a mineração no país, enfatizando a dimensão do desastre e de seus impactos ambientais e humanos, e denunciando o modelo de gestão do desastre das empresas responsabilizadas. Concomitante a denúncia à OEA, foi realizado um ato público denominado "Dia $1^{\circ}$ de Abril: dia das mentiras da Samarco", em frente a sede do governo estadual, em Vitória. Logo depois, o FCDRD promoveu a primeira Audiência Pública, em 29 de junho de 2016, voltada a dar voz aos atingidos do estado até então invisibilizados e inaudíveis, organizada junto com a Comissão Parlamentar Interestadual do Rio Doce-CIPE, na Assembleia Legislativa do Espírito Santo-ALES. Em 07 de setembro de 2016, o FCDRD organizou com a Arquidiocese da Igreja Católica de Vitória a passeata "Grito dos Excluídos: a vida em primeiro lugar", evento que inseriu o tema do desastre da Samarco no calendário da Igreja Católica com caminhada e ato público programados anualmente. A marcha reuniu 5 mil pessoas nas ruas e foi performatizada simbolicamente com um tecido marrom de 500 metros e peixes de papel afixados, representando a tragédia ambiental no Rio Doce. Em evento posterior, o protesto intitulado "Manifestação em defesa do Rio Doce" abalizou o primeiro aniversário do desastre, em 05 de novembro de 2016, evento esse programado para se repetir nos aniversários seguintes, acompanhado de seminários com depoimentos dos atingidos e audiências públicas com autoridades. Por fim, no mesmo mês o FCDRD junto com a Diocese de Colatina realizou um encontro com o presidente nacional da Ordem dos Advogados do BrasilOAB. Um ano depois, em 28 de novembro de 2017, uma atingida do município de Baixo Guandu, ativista do FCDRD e do Movimento Nacional de Atingidos por Barragens-MAB expressou seu depoimento no Conselho de Direitos Humanos da ONU, compondo a denúncia formalizada pela Conectas Direitos Humanos.

Os repertórios de ação coletiva acionados pelos movimentos, ativistas e organizações participantes dos Fóruns combinam formas tradicionais de ação com performances inovadoras que carregam e transmitem seus significados e sentidos atribuídos pelos sujeitos mobilizados e pelos atingidos.

É mister ressaltar que os repertórios de ação coletiva e performances do Fórum Capixaba em Defesa do Rio Doce e os respectivos fóruns locais se desenvolvem no contexto estadual de atuação de um dos movimentos sociais mais expressivos na luta pelos atingidos por barragens, a saber, o MAB (Movimento Nacional dos Atingidos por Barragens), o qual se integrou a coordenação do FCDRD. O MAB emergiu no território capixaba logo após o rompimento da barragem de Fundão e a chegada da lama no estado, em novembro de 2015. Com ações iniciadas em Colatina através do apoio da estrutura de organização nacional do movimento, da Diocese municipal e de ativistas de outros estados que passaram a residir no estado, o MAB logo expandiu suas ações para outros territórios capixabas atingidos ao longo da calha e foz do Rio Doce, construindo grupos de base em torno da identidade de atingido, fomentando a emergência de novos ativistas e criando a coordenação estadual do movimento. No Espírito Santo, o MAB foi o principal 
responsável pela criação das Comissões de Atingidos nos municípios afetados, com o apoio do FCDRD e ratificadas pelo Ministério Público Federal (MPF) e Defensoria Pública Estadual (DPE-ES). Ademais, foi um dos principais mobilizadores dos atingidos e promotores de ações disruptivas como as ocupações de prédios e de vias férreas, agindo para influenciar os acordos (Termos de Ajustamento de CondutasTACs) e pressionando a empresa para abertura de novas negociações em torno das reparações dos danos.

Por outro lado, cabe igualmente destacar que as iniciativas de mobilização e de articulação entre os atores sociais na promoção de ações comuns em prol dos atingidos consideram não somente os movimentos, fóruns e ativistas emergentes, mas integra também as associações civis, religiosas e movimentos sociais preexistentes no estado, como o movimento de direitos humanos (MEDH e MNDH), o Centro de Defesa de Direitos Humanos da Serra (CDDH), o Centro de Apoio aos Direitos Humanos (CADH) e o Conselho Estadual de Direitos Humanos (CEDH), o movimento de trabalhadores rurais (MPA e MST) e várias ONGs ambientalistas, além dos segmentos da Igreja Católica como a Arquidiocese de Vitória e a Diocese de Colatina (CJP, Cáritas e diversas Pastorais), bem como as associações de pescadores e as associações de moradores dos municípios atingidos. Por sua vez, para as ações articuladas em nível nacional e internacional, as ONGs de direitos humanos com atuação interfronteiriça como a Justiça Global e a Conectas Direitos Humanos são ativadas e se fazem presentes, particularmente na estratégia multiescalar de nacionalização e internacionalização da causa. Neste propósito, partes do Estado apoiadoras da causa dos atingidos também são articuladas para garantia das reparações, sobretudo o sistema de justiça através do MPF, do MPT e da DPE-ES.

Assim, a emergência de novos ativistas, movimentos e novas formas de mobilização têm sido verificadas neste contexto de pós-desastre. A performance dos atores, organizações e movimentos, suas interpretações e inovações no repertório de ação coletiva vão se modificando ao longo do tempo, estando em constante reconfiguração e ressignificação. As iniciativas de organização popular dos atingidos em ações coletivas voltadas às reivindicações e às proposituras, são acompanhadas da construção coletiva das identidades de atingido. Em especial, a formação de grupos de base pelos atingidos constituiu uma estratégia de organização popular, consubstanciada na criação de fóruns locais, comissões de atingidos, grupos de trabalho e comitês de deliberação, conforme demonstrado. Neste propósito de organização das bases populares, as organizações de movimentos sociais historicamente estabelecidas em nível estadual e nacional, com trajetórias de atuação na formação política de novas coletividades e grupos sociais e na articulação de redes de movimentos assumiram um papel fundamental como "incubadoras para o movimento social contencioso" (CARLOS, 2018). O Movimento Estadual de Direitos Humanos no Espírito Santo (MEDH) ${ }^{15}$, em conjunto com o Movimento Nacional de Direitos Humanos (MNDH) e segmentos da Igreja Católica ${ }^{16}$, e o Movimento Nacional de Atingidos por Barragens (MAB) desempenharam esta função de incubadoras, indo

\footnotetext{
${ }^{15}$ No Espírito Santo, o Movimento Estadual de Direitos Humanos é formado pelo CDDH-Serra, CEDH, CADH e organizações da Igreja Católica como CJP, Cáritas e Pastorais (CARLOS, 2015 e 2014).

${ }^{16}$ No contexto do desastre, destaca-se da Igreja Católica as ações de mobilização e de organização popular da Arquidiocese de Vitória através da CJP, Caritas e CPT, e da Diocese de Colatina através das Pastorais e Caritas.
} 
além do papel de aliados, porque agiram na formação organizacional e identitária dos ativistas e atingidos mobilizados.

Por seu turno, às mobilizações se somaram as Audiências Públicas protagonizadas por atingidos, nos diversos municípios afetados e na capital, além das ações impetradas no Judiciário, como a Ação Cível Pública pelo MPF que criminaliza as mineradoras responsabilizadas pelo desastre socioambiental ${ }^{17}$. Neste contexto do desastre, observa-se um uso renovado das audiências públicas enquanto uma esfera pública de vocalização dos atingidos e de articulação dos atores, especialmente quando são protagonizadas por atingidos e promovidas por organizações mobilizadas na defesa dos direitos humanos e dos direitos de cidadania destes. Assim, as audiências públicas também podem se constituir como um espaço de inovação e de confrontação, no contexto de conjuntura crítica. Mormente conhecida como esfera institucional limitada à contestação pública, a audiência pública tem se convertido em espaço para vocalização dos atingidos e publicização de sua causa. Sobretudo são promovidas pelo legislativo estadual (CIPE), pela DPE-ES, pelo MAB e pelo $\mathrm{FCDRD}^{18}$. Protagonizadas por atingidos mobilizados, movimentos sociais e associações dos segmentos atingidos, a responsabilização da empresa causadora do desastre e a garantia dos direitos de reparação dos atingidos são as principais motivações ao engajamento dos atores. Em termos organizacionais, a audiência pública possui composição mista (atores estatais e atores da sociedade civil e atingidos) sendo conduzida pelos atores institucionais. A dinâmica de organização evidencia o caráter interativo dessa arena, onde as organizações sociais e atingidos possuem o direito à fala e à argumentação pública. Cabe destacar, no entanto, que enquanto arena de interação socioestatal, nas audiências públicas, o direito à fala, ao depoimento-denúncia e à escuta é desacompanhado de obrigatoriedade de posicionamento das instituições do Estado e autoridades presentes e de decisões vinculantes.

Nestes espaços, o padrão de interação com o Estado é discursivamente conflituoso, onde os movimentos e organizações da sociedade civil se utilizam de repertórios de ação contenciosos e de frames de contestação para expressar suas demandas, proposições e identidades (CARLOS, GOMES, 2017). Em suma, as audiências públicas consistem em uso renovado do formato porque atores sociais ou seus apoiadores as têm promovido e as mesmas têm sido um espaço para vocalização e expressão. Porém, resta como um espaço sem resolutividade porque o poder de decisão está deslocado do Estado para a Empresa responsabilizada pelo desastrecrime.

Esta análise das formas de mobilização da sociedade civil, seus enquadramentos interpretativos, repertórios de ação coletiva e performances, formas organizacionais, permite apreender os processos de inovação e mudança

\footnotetext{
17 Para uma análise das ações judiciais do desastre do Rio Doce, vide: DORNELAS et. alli (2016).

${ }^{18}$ Considerando o período de novembro de 2015 a setembro de 2016 foram realizadas 14 audiências públicas, distribuídas nos municípios de Vitória, Colatina, Baixo Guandu e Linhares, sendo: 57\% organizadas pela ALES (Assembleia Legislativa do ES), especificamente CIPE e Comissão de Meio Ambiente, a primeira delas organizada em conjunto com o Fórum Capixaba em Defesa do Rio Doce; e 43\% promovidas pela DPE-ES (Defensoria Pública Estadual); sendo rara a atuação de governos municipais. (CARLOS, GOMES, 2017). Outras audiências públicas continuaram sendo organizadas no período subsequente, porém com menor frequência.
} 
organizacional no contexto de conjuntura crítica do desastre. Demonstra ainda o uso combinado de repertórios através de ações extrainstitucionais (fóruns e manifestações diversas) e formatos institucionalizados (audiências públicas) ${ }^{19}$. Porém, a despeito das mobilizações sociais e arenas de contestação estabelecidas, as decisões públicas das autoridades e empresas responsabilizadas tardam a se configurarem como políticas públicas complexas, integradas e longínquas no tempo. Em geral, as decisões públicas ainda se situam no plano das medidas emergenciais, muitas das quais firmadas sem a participação dos atingidos e a despeito da sua organização popular.

\section{3 À guisa de conclusão}

O artigo buscou demonstrar, por um lado, a criação de decisões e instrumentos de políticas públicas na esfera dos governos e, por outro lado, a emergência de formas de participação e contestação no campo da sociedade civil, no contexto de conjuntura crítica do desastre socioambiental.

O levantamento sistemático nos Diários Oficiais dos municípios, ainda que em fase exploratória e relativo a período relativamente curto, revelou mudanças importantes nos padrões de relação entre as instituições e os atores estatais. Embora seja cedo para conclusões substantivas sobre o papel dos conselhos frente ao desastre, verificou-se que os mesmos emitiram poucas resoluções no período analisado. Por outro lado, o contexto de conjuntura crítica, como o desastre em questão, impulsionou mudanças institucionais no Estado através da criação de novas decisões e instrumentos de políticas públicas de três diferentes tipos: representativo, regulatório e fiscalizatório; que mobilizaram diferentes recursos organizacionais em múltiplas arenas (executivo, legislativo, sistema de justiça) e nas esferas estadual e municipal.

Por sua vez, o contexto do desastre socioambiental no Rio Doce incentivou a emergência de mobilizações em prol das populações atingidas, ainda que não seja o único fator explicativo, caracterizado pelo uso de repertórios de ação coletiva inovadores e performáticos por movimentos sociais, organizações civis, ativistas, fóruns da sociedade civil e apoiadores da causa. A análise buscou o aprofundamento sobre as formas de ação coletiva contestatórias com base no exame dos repertórios de ação coletiva e performances, dos enquadramentos interpretativos e dos padrões de interação em duas modalidades emergentes - os fóruns da sociedade civil e as audiências públicas. Seja nas mobilizações públicas seja nos fóruns da sociedade civil seja nas audiências públicas o papel de movimentos sociais emergentes e dos preexistentes foi fundamental na criação de novos formatos de organização popular. Alguns deles funcionaram como incubadores para o movimento social contencioso, agindo na sua formação organizacional e identitária. Ademais, influíram na adoção da estratégia multiescalar de nacionalização e internacionalização da causa através da articulação da rede de ativismo interfronteiriça. Caberá a estudos futuros investigar

19 Sobre a combinação entre múltiplos repertórios de ação e interação (extrainstitucionais e institucionais) pelos movimentos sociais no Brasil, vide: ABERS; SERAFIM; TATAGIBA, 2014; CARLOS, 2015; DOWBOR, 2012. 
a capacidade de influência política destas mobilizações e formatos de participação sobre as decisões e políticas públicas.

Resta ainda saber os desdobramentos dessas novas instituições e os potenciais conflitos entre os atores que as ocupam, assim como se elas vão permanecer ou não. Se partimos do pressuposto da mútua constituição nas relações entre o Estado e a sociedade civil e observamos mudanças organizacionais nos atores sociais e institucionais nos atores políticos, a questão que se coloca é em que medida as mudanças no Estado impactam nas mudanças na sociedade civil e vice-versa.

Em última análise, nota-se uma movimentação tanto dos atores sociais, quanto dos atores estatais que instituíram novos instrumentos de políticas públicas após o desastre que orientam as relações entre o governo, a sociedade civil e os interesses de mercado, representados pelas empresas envolvidas, conquanto os novos dispositivos de representação incluam mais componentes técnicos do que componentes sociais.

\section{REFERÊNCIAS}

ABERS, R; SERAFIM, L.; TATAGIBA, L. Repertórios de interação Estado-sociedade em um Estado heterogêneo: a experiência da era Lula. Dados, Rio de Janeiro, 57, 2, p. 325-357, 2014.

ACSELRAD, H. Conflitos Ambientais no Brasil. Rio de Janeiro: Relume Dumará: Fundação Heinrich Boll, 2004.

BENFORD, R. D.; SNOW, D. A. Framing Processes and Social Movements: An Overview and Assessment. Annual Review of Sociology, 26, p. 611-639, 2000.

CARLOS, E. A construção de encaixes institucionais e domínio de agência do movimento popular urbano: mecanismos e configurações. In: GURZA LAVALLE; CARLOS; DOWBOR; SZWAKO (orgs.) Movimentos Sociais e Institucionalização: Políticas Sociais, Raça e Gênero no Brasil pós-transição. Rio de Janeiro: Eduerj, 2019, prelo.

CARLOS, E. Movimentos sociais e instituições participativas: efeitos do engajamento institucional no contexto pós-transição. Belo Horizonte: Fino Traço, 2015.

CARLOS, E. Mudanças e continuidades no movimento de direitos humanos: padrões organizacionais, relacionais e discursivos. Opinião Pública, 20, 3, p. 450-479, 2014.

CARLOS, E.; GOMES, P.A. Relatório Final do Subprojeto: Interações entre movimentos sociais e Estado no contexto das violações de direitos humanos na Bacia do Rio Doce. Universidade Federal do Espírito Santo, Programa Institucional de Iniciação Científica. Vitória: NUPAD, UFES, Mimeo, 2017. 
CARLOS, E.; GOMES, P. A. Relatório Final do Subprojeto: A relação movimentos sociais e Estado no Fórum SOS Rio Doce Colatina. Universidade Federal do Espírito Santo, Programa Institucional de Iniciação Científica. Vitória: NUPAD, UFES, Mimeo, 2018.

CARLOS, E.; MARTINS, L.P. Relatório Final do Subprojeto: Os movimentos sociais e a tragédia no Rio Doce: estudo de caso do Fórum Capixaba em Defesa da Bacia do Rio Doce. Universidade Federal do Espírito Santo, Programa Institucional de Iniciação Científica. Vitória: NUPAD, UFES, Mimeo, 2017.

CARLOS, E.; SOUZA, L.A.M. Mobilização social e instituições participativas no contexto do desastre no Rio Doce. Anais do $11^{\circ}$ Encontro da $A B C P$, Curitiba, 31 de julho a 3 de agosto de 2018.

DIANI, M; BISON, I. Organizações, coalizões e movimentos. Revista Brasileira de Ciência Política, Brasília, 3, p. 219-250, 2010.

DORNELAS, R.S.; LIMA, L.B.; ZANOTELLI, A.G.C.; AMARAL, J.P.P; CASTRO, J.S.; DIAS, T. Ações Civis Públicas e Termos de Ajustamento de Conduta no caso do desastre ambiental da Samarco: considerações a partir do Observatório de Ações Judiciais. In: MILANEZ, B.; LOSEKANN, C. (Orgs.) Desastre no vale do Rio Doce: Antecedentes, impactos e ações sobre a destruição. Rio de Janeiro: Folio digital: Letra e imagem, 2016, p. 339-370.

DOWBOR, M. A arte da institucionalização: estratégias de mobilização dos sanitaristas (1974-2006). Tese de Doutorado (Ciência Política), Faculdade de Filosofia, Letras e Ciências Humanas, Universidade de São Paulo/USP, 2012.

EVANS, P.; RUESCHEMEYER, D.; SKOCPOL, T. Bringing the State Back in. Cambridge: Cambridge University Press, 1985.

FERREIRA, S. Marcas da colonialidade do poder no conflito entre a mineradora Samarco, os povos originários e comunidades tradicionais do Rio Doce. In: MILANEZ, B.; LOSEKANN, C. (Orgs.) Desastre no vale do Rio Doce: Antecedentes, impactos e ações sobre a destruição. Rio de Janeiro: Folio digital: Letra e imagem, 2016, p. 267-307.

GURZA LAVALLE, A., VOIGT, J. E SERAFIM, L. O que fazem os conselhos e quando o fazem? Padrões decisórios e o debate dos efeitos das instituições participativas. Dados, Rio de Janeiro, 59, 3, p. 609-650, 2016.

GURZA LAVALLE, A; CARLOS, E; DOWBOR, M; SZWAKO, J. Movimentos sociais, institucionalização e domínios de agência. Texto para Discussão CEM, Nº19, São Paulo: CEM, p. 1-40, 2017.

GURZA LAVALLE, A; HOUTZAGER, P; CASTELLO, G. La construcción política de las sociedades civiles, In: GURZA LAVALE, A. (org.), El horizonte de la política. Brasil y 
la agenda contemporánea de investigación en el debate internacional, México, CIESAS, 2011, p. 207-267.

HALPERN, C.; LE GALÈS, P. No Autonomous Public Policy Without ad hoc instruments: a comparative and longitudinal analysis of the European Union's environmental and urban policies. Presses de Sciences Po, Revue française de science politique (English), 61, 1, p. 43-67, 2011.

JOBERT, B.; MULLER, P. L'État en Action: politiques puliques et corporatismes. Paris, PUF, 1987.

LASCOUMES, P.; LE GALÈS, P. Introduction: Understanding Public Policy through Its Instruments-From the Nature of Instruments to the Sociology of Public Policy Instrumentation. Governance: An International Journal of Policy, Administration, and Institutions, 20, 1, p. 1-21, 2007.

LEONARDO, F.; IZOTON, J.; VALIM, H. CREADO, E. TRIGUEIRO, A. SILVA, B. DUARTE, L. SANTANA. N. Rompimento da barragem de Fundão (SAMARCO/VALE/BHP BILLITON) e os efeitos do desastre na foz do Rio Doce, distritos de Regência e Povoação, Linhares (ES). Relatório de pesquisa. GEPPEDES. Vitória: UFES, abr., Mimeo, 2017.

LOSEKANN, C. Impactos socioambientais no Espírito Santo da ruptura da barragem de rejeitos da Samarco. Relatório preliminar. ORGANON. Vitória: UFES, Nov./Dez., Mimeo, 2015.

MARQUES, E. As políticas públicas na Ciência Política. In: MARQUES, E.; FARIA, C. A.P. (org.). A política pública como campo multidisciplinar. SP: Editora Unesp; RJ: Ed. Fiocruz, 2013.

MAHONEY, J.; THELEN, K. Explaining Institutional Change: Ambiguity, Agency, and Power. Cambridge. Cambridge University Press, 2010.

SKOCPOL, T. Protecting soldiers and mothers: the political origins of social policy in the United States. Cambridge: Belknap Press/Harvard University Press, 1992.

SOUZA, C. Políticas Públicas: uma revisão da literatura. In: Sociologias, Porto Alegre, ano 8, n. 16, jul/dez, p. 20-45, 2006.

SOUZA, L.A.M.; CHRISTO, R.S. Relatório Final do Subprojeto: Os Impactos da Tragédia Socioambiental do Rio Doce nas políticas públicas do município de Linhares (ES). Universidade Federal do Espírito Santo, Programa Institucional de Iniciação Científica. Vitória: NUPAD, UFES, Mimeo, 2017.

SOUZA, L.A.M. "Virada institucional”: o debate sobre o papel das instituições e dos atores nas três gerações de estudos sobre o Orçamento Participativo. In: BIB, São Paulo, n. 79, $1^{\circ}$ semestre de 2015 (publicada em outubro de 2016), p. 83-103, 2016. 
SOUZA, L.A.M; CARLOS, E. Instituições participativas e mobilização social no contexto do desastre no Rio Doce. Anais do $42^{\circ}$ Encontro da ANPOCS, Caxambu, 22 a 25 de outubro de 2018.

TILLY, C. Regime and repertoire. Chicago, The University of Chicago Press, 2008.

TILLY, C.; TARROW, S. Contentious Politics. Boulder, Colo.: Paradigm Publishers, 2007.

Luciana Andressa Martins Souza. Doutora em Ciência Política (UFSCar) e PósDoutorado (CEBRAP). Professora do Departamento de Ciências Sociais e do Programa de Pós-Graduação em Ciências Sociais da UFES e Pesquisadora do Núcleo Participação e Democracia (NUPAD/UFES), do Núcleo Democracia e Ação Coletiva) (NDAC/CEBRAP) e da Rede ComRIOComMAR. lu.ufscar@hotmail.com

Euzeneia Carlos. Doutora em Ciência Política pela Universidade de São Paulo (USP), Mestre em Planejamento Urbano e Regional pela Universidade Federal do Rio de Janeiro (IPPUR/UFRJ). Professora do Programa de Pós-Graduação em Ciências Sociais da Universidade Federal do Espírito Santo (UFES). Coordenadora do Núcleo Participação e Democracia (NUPAD/UFES), pesquisadora do Núcleo Democracia e Ação Coletiva (NDAC/CEBRAP) e da Rede ComRIOComMAR. euzeneiacarlos@gmail.com

Como citar: SOUZA, Luciana Andressa Martins; CARLOS, Euzeneia. Políticas públicas e mobilização social no contexto do desastre no Rio Doce. Redes, Santa Cruz do Sul, v. 24, n. 2, p. 56-80, may 2019. ISSN 1982-6745. Disponível em: https://doi.org/10.17058/redes.v24i2.13040. 